\title{
EL ARTÍCULO 1705(3) DEL TRATADO DE LIBRE COMERCIO DE AMÉRICA DEL NORTE Y SU INTERPRETACIÓN POR LA SUPREMA GORTE DE JUSTICIA DE LA NAGIÓN
}

\author{
Roberto GARZA BARBOSA* \\ SUMARIO: I. Introducción. II. El artículo 1705 del TLCAN. III. La Ley Fede- \\ ral del Derecho de Autor. IV. Las sentencias de la Suprema Corte de Fusticia de la \\ Nación. V. Conclusiones.
}

\section{INTRODUCGIÓN}

El presente estudio muestra el alcance del artículo 1705(3) del Tratado de Libre Comercio de América del Norte (TLCAN o NAFTA, por sus siglas en inglés). Asimismo, describe el alcance de dicho precepto legal en varios desarrollos jurídicos importantes en el sistema jurídico mexicano. Primeramente, estamos hablando de un conjunto de reformas a la Ley Federal del Derecho de Autor, que adicionan un derecho de regalías, con carácter de irrenunciable. Después, se abordan dos sentencias de la Suprema Corte de Justicia de la Nación: un amparo en revisión en el que se analiza la constitucionalidad de dicha reforma y posteriormente una contradicción de tesis.

En ese mismo orden se abordan los temas; primero el artículo 1705(3) del TLCAN, sus alcances, contexto histórico e interpretación. Posteriormente se analizan las reformas para concluir con las sentencias de la $\mathrm{Su}-$ prema Corte de Justicia de la Nación.

* Profesor del Departamento de Derecho del Tecnológico de Monterrey, campus Monterrey, así como de la Escuela Nacional de Humanidades y Ciencias Sociales de la misma institución. Maestro (2001) y doctor (2006) en derecho internacional y comparado por la Universidad de Tulane (Nueva Orleáns, Estados Unidos); maestro en derecho comercial internacional por el Tecnológico de Monterrey, campus Monterrey (1999); licenciado en derecho por la Universidad Autónoma de Nuevo León (1997). Pertenece al Sistema Nacional de Investigadores del Conacyt.

Boletín Mexicano de Derecho Comparado nueva serie, año XLVIII, núm. 144, septiembre-diciembre de 2015, pp. 1231-1252

D. R. C 2015. UNAM, Instituto de Investigaciones Jurídicas. 


\section{EL ARTÍCULO 1705 DEL TLGAN}

El capítulo XVII del TLCAN tiene los mismos orígenes que el Acuerdo sobre los Aspectos de los Derechos de Propiedad Intelectual Relacionados con el Comercio (ADPIC o TRIPs, por sus siglas en inglés). Lo anterior se debe a que los negociadores del TLCAN asumieron como propio el borrador del ADPIC emitido en 1991, descartando así diversos borradores que ya tenían elaborados. ${ }^{1}$ Consecuentemente, en materia de propiedad intelectual el TLCAN tiene provisiones y conceptos muy parecidos a aquellos encontrados en el ADPIC. ${ }^{2}$

Sin embargo, existen algunas diferencias entre el ADPIC y el capítulo XVII del TLCAN. Se considera que este último tiene mayores exigencias sobre algunos temas que el ADPIC. Por ejemplo, mayores requerimientos de trato nacional y menor término para implementar sus provisiones en la legislación nacional de cada país miembro. ${ }^{3}$ Por otra parte, mientras el ADPIC no contempla nada al respecto, el capítulo XVII del TLCAN establece para los titulares de derechos de autor y derechos conexos, su libre disposición o transferencia. ${ }^{4}$ Lo anterior se desprende del artículo 1705(3)(a) del TLCAN: "cada una de las partes dispondrá que para los derechos de autor y derechos conexos: (a) cualquier persona que adquiera o detente derechos económicos pueda, libremente y por separado, transferirlos mediante contrato para efectos de explotación y goce por el cesionario....". 5

La interpretación literal y predominante de esta provisión establece que el derecho de disposición cubre el derecho de transferir derechos económicos, así como el derecho de ejercer libremente los derechos así adqui-

1 Véase Woodward, Martin D. H., "TRIPs and NAFTA's Chapter 17: How Will Trade-Related Multilateral Agreements Affect International Copyright?", Texas International Law fournal, vol. 31, 1996, pp. 269, 273-274.

2 Idem.

3 Véase Dinwoodie, Graeme B. et al., International Intellectual Property Law and Policy, Newark, Lexis Nexis, 2001, p. 563.

4 Véase Ilardi, Alfredo y Blakeney, Michael, International Encyclopedia of Intellectual Property Treaties, Oxford, Oxford University Press, 2004, p. 980; Woodward, Martin D. H., "TRIPs and NAFTA's...", cit., p. 280.

5 TLCAN, art. 1705(3). 
ridos por contrato. ${ }^{6}$ Sin embargo, esta provisión es contraria al carácter inalienable de los derechos de autor común en los países de la tradición romano germánica.

Tal carácter de inalienable proviene del pensamiento de Immanuel Kant, quien establecía que los derechos de autor son derechos personales o de personalidad en lugar de derechos de propiedad o reales, ya que los mismos expresan la personalidad interior del propio autor. ${ }^{7}$ Los visualizaba como un discurso tripartita y explicaba la diferencia entre el derecho que tiene el autor sobre su discurso escrito, el derecho que tiene el editor imprimiendo con autorización del autor, y el derecho que tiene bajo el derecho civil el poseedor del libro, con lo cual creó una de las doctrinas que más han influido en la tradición romano germánica en relación con los derechos de autor. ${ }^{8}$ Todo ello lo inició preguntándose ¿qué es un libro? ${ }^{9}$ $\mathrm{Al}$ interpretar esta discusión de Kant, sus seguidores Otto von Gierke y Philipp Allfeld, crearon la doctrina monista, aquella que en lugar de dividir los derechos de autor en patrimoniales y morales, establece un solo cuerpo de derechos. ${ }^{10}$ Además, establecieron que por ser un derecho de personalidad en lugar de una cosa externa, los derechos de autor no se pueden vender o transferir. ${ }^{11}$

Esta limitación sobre la voluntad del autor a transferir sus derechos, también está basada en la noción de que un desigual poder de negociación podría producir contratos desventajosos para los autores. ${ }^{12}$ Las limitaciones a la libre disposición o venta de derechos pueden variar de un sistema jurídico a otro. En algunos sistemas jurídicos, dichas limitaciones

6 Véase Golsby, Sharan L., "Protection of Intellectual Property Rights under NAFTA", NAFTA: Law and Business Review of the Americas, vol. 5, 1998, pp. 5 y 19. También Woodward, Martin D.H., "TRIPs and NAFTA's...", cit., p. 280.

7 Véase Kant, Immanuel, The Philosophy of the Law: An Exposition of the Fundamental Principles of Jurisprudence as the Science of Right, 1796, trad. al inglés de William Hastie, Edimburgo, 1887, pp. 129-131; Netanel, Neil, "Alienability Restrictions and the Enhancement of the Author Autonomy in United States and Continental Copyright Law", Cardozo Arts. E Entertainment Law fournal, vol. 12, 1994, pp. 1, 7.

8 Idem.

9 Ibidem, pp. 129-131.

10 Véase Netanel, Neil, "Alienability Restrictions...", cit., p. 20.

11 Ibidem, pp. 20 y 21.

12 Véase Lypszyc, Delia, Copyright and Neighboring Rights, París, Unesco, 1999, p. 278. 
pueden incluir requisitos en la forma de los contratos, obligando a las partes a que los mismos consten por escrito, asimismo pueden establecer que ciertos derechos sean irrenunciables, e incluso unos sistemas jurídicos pueden limitar el término de la transmisión o prohibir totalmente la transferencia de derechos. ${ }^{13}$

El sistema jurídico mexicano adopta en parte la teoría monista de Kant, pero solamente en lo concerniente a la libre disposición de estos derechos. Es decir, la ley divide los derechos en patrimoniales y morales, es decir, hasta aquí no se puede decir que es monista; sin embargo, limita la libre transmisión de derechos. Lo anterior se encuentra reflejado principalmente en los artículos 30, 31 y 33 de la Ley Federal del Derecho de Autor. Si bien dichos artículos no prohíben totalmente la transmisión de derechos, sí limitan la libre disposición de los mismos. El segundo párrafo del artículo 30 establece que las licencias deberán ser onerosas y temporales, en tanto el tercer párrafo de dicho precepto legal establece, bajo pena de nulidad, que toda licencia, acto o convenio por el que se transmitan derechos patrimoniales debe constar por escrito. El artículo 31 establece el derecho irrenunciable a una participación proporcional en los ingresos por la explotación de la obra cedida, o bien una remuneración fija. Asimismo, el artículo 33 establece restricciones en cuanto a la temporalidad de la transmisión de los derechos, primeramente fijando cinco años en caso de omisión del término en un contrato determinado, además de limitar cualquier transferencia a un término no mayor de 15 años, a menos que la "naturaleza de la obra o la magnitud de la inversión requerida..." así lo justifique. Estas provisiones son claramente contrarias al término "libremente", establecido por artículo 1705(3) del TLCAN, ya que cualquier limitación a la libre disposición es contraria a dicho precepto.

Si un sistema jurídico ha adoptado la doctrina monista de Kant, significa que una obra se considera parte de la personalidad del propio autor y no una cosa externa que se pueda vender o disponer libremente. ${ }^{14}$ Esto es totalmente distinto en los sistemas jurídicos que consideran la obra como una cosa externa o la consideran un privilegio por tiempo determinado que tiene el propósito de incentivar la producción de más obras. En estos últimos casos, el autor tiene la libertad de transferir contractualmente su

13 Ibidem, p. 277.

14 Véase Netanel, Neil, "Alienability Restrictions...", cit., pp. 20 y 21. 
obra, de la misma manera que podría transferir la propiedad de una cosa física (inmueble, automóvil) o cualquier derecho real. ${ }^{15}$

El ADPIC no tiene provisión alguna que prevea la libre transferencia de derechos de autor o derechos conexos similar al artículo 1705(3) del TLCAN, citado anteriormente. Ello debido a que la gran mayoría de los ahora Estados miembros, que en ese momento negociaban el acuerdo, pertenecen a la tradición romano germánica, incluyendo todos los países de Europa continental. Así, un gran número de estos países cuyas legislaciones prevén restricciones a la libre transferencia de derechos, se opusieron a una provisión que asegurara la libre transferencia de los mismos. ${ }^{16}$ Dichos países, en su conjunto tenían más poder de negociación del que tuvo México cuando negoció el TLCAN con los Estados Unidos y Canadá, es por eso que mientras el TLCAN obliga la libre transferencia de derechos, el ADPIC no contempla el tema. Es decir, no se trata de un accidente o una omisión provocada por el descuido, sino de un complejo proceso de negociación del tratado.

En el caso del TLCAN, México es el único país de tradición romano germánica. Sin embargo, aceptó esta provisión debido a la presión ejercida por los países de tradición common law durante la negociación del acuerdo. ${ }^{17}$ Es justo mencionar que los negociadores mexicanos aceptaron estas provisiones con el propósito de alcanzar los beneficios económicos de dicho tratado. ${ }^{18}$ Sin embargo, como se muestra a continuación, el artículo 1705(3) del TLCAN no ha sido incorporado ni aplicado en el sistema jurídico mexicano.

15 Ibidem, pp. 18-22; Correa, Carlos M., Trade Related Aspects of Intellectual Property Rights. A Commentary on the TRIPs Agreement, Nueva York-Oxford, 2007, p. 117.

16 Véase Reindl, Andreas P., "Choosing Law in Cyberspace: Copyright Conflicts on Global Networks", Michigan Fournal of International Law, vol. 19, 1998, pp. 799 y 866-870; Geller, Paul E. y Nimmer, Melville B., International Copyright Law and Practice, Nueva York, Lexis Nexis, 2003, pp. 246-250; id., "Conflicts of Laws in Copyright Cases: Infringement and Ownership Issues", fournal of the Copyright Society of the U.S.A., vol. 51, 2004, pp. 315, 356-358.

17 Ryan, Michael P., Knowledge Diplomacy: Global Competition and the Politics of Intellectual Property, Washington, Brookings Institution Press, 1998, p. 3.

18 Sommer, Heidi, "The Economic Benefits of NAFTA to the United States and Mexico", National Center for Policy Analysys Brief Analysys, vol. 619, 2008, pp. 1 y 2, disponible en http://research.policyarchive.org/8111.pdf(visitada el 6 de enero de 2015). 


\section{LA LEy FederAl DEL DeREGHO DE AUtOR}

El 23 de julio de 2003, se publicó en el Diario Oficial de la Federación un decreto de reformas a varios preceptos de la Ley Federal del Derecho de Autor. ${ }^{19}$ Entre otras cuestiones, las reformas establecieron en favor de: a) autores; $b$ ) artistas, intérpretes y ejecutantes; así como de $c$ ) productores de fonogramas, un derecho de remuneración equitativa por la comunicación o transmisión pública de sus obras. En este sentido, los artículos 117 bis, y 131 bis del decreto, establecieron el derecho de remuneración por el uso o explotación con fines de lucro directo o indirecto, "por cualquier medio, comunicación pública o puesta a disposición" para artistas, intérpretes, ejecutantes, y productores de fonogramas respectivamente. En cuanto a artistas, intérpretes y ejecutantes, el artículo 117 bis, estableció además, que este derecho es irrenunciable. Asimismo, el artículo 26 bis, fijó el mismo derecho para titulares de derechos de autor, dándole también carácter de irrenunciable.

Para comprender el origen de este derecho de remuneración equitativa, abordaremos algunos aspectos relevantes de la Convención de Roma. El artículo 7o. de la misma, contempla los derechos de los artistas intérpretes y ejecutantes de una manera un tanto limitada. Básicamente sólo tienen derechos sobre sus interpretaciones no fijadas. Ello se debe a que cuando autorizan la fijación de su interpretación, entonces sus derechos se agotan. Es decir, no tienen derechos una vez que han autorizado la fijación de sus interpretaciones. Sus derechos se limitan a prevenir la transmisión, la comunicación al público, la fijación de sus interpretaciones en vivo, así como la reproducción de aquellas interpretaciones que han sido fijadas sin su autorización. Acorde con la anterior interpretación, el artículo 19 de la Convención de Roma establece que una vez que el artista ha consentido la incorporación de su interpretación en una obra visual o audiovisual, los derechos establecidos por el artículo 7o. se agotarán. Ello también resulta obvio cuando el artista consiente la fijación de su obra en algún otro tipo de obra, como el fonograma, ya que el artículo 7o. solamente habla de derechos, cuya fijación no ha sido autorizada. Entonces si el artista, intérprete o ejecutante le autoriza al productor de un fonogra-

19 Diario Oficial de la Federación, publicado el 23 de julio de 2003, que reforma y en su caso emite los artículos 26 bis, 27, 78, 83, 86, 88, 89, 9092 bis, 117 bis, 118, 122, 131 bis, 132, 133, 134, 146, 213, y 216 bis de la Ley Federal del Derecho de Autor. 
ma la fijación de una interpretación, no le quedará derecho alguno bajo el artículo $7 \mathrm{o}$.

Lo limitado de los derechos de los artistas, intérpretes y ejecutantes bajo la Convención de Roma es el resultado de una aparente tensión entre éstos y los autores, ya que mientras aquéllos interpretan y ejecutan la letra y la música compuesta por los autores, éstos todavía conservan derechos sobre esas letras y música, incluyendo, entre otros, el derecho de reproducción, el de comunicación al público y el de transmisión..$^{20}$ Por lo tanto, sería un riesgo para el autor si el artista, intérprete o ejecutante evitara la explotación de la obra por parte del autor, oponiéndose a la transmisión, o reproducción de su interpretación de dicha obra. ${ }^{21}$ Aunque esta situación es poco probable debido a que iría en contra de los propios intereses del artista, intérprete o ejecutante, los riesgos persisten y es por eso que la Convención de Roma tiene derechos tan limitados para éstos, cubriendo solamente interpretaciones que no han sido fijadas o aquellas que el artista o intérprete no ha autorizado su fijación. ${ }^{22}$ De otra manera, tanto el artista, intérprete o ejecutante, como el autor tendrían derechos sobre el mismo objeto. Sin embargo, el derecho contenido en el artículo 12 de la Convención de Roma ha sido caracterizado como una respuesta a los derechos tan limitados que la propia Convención otorga a artistas, intérpretes y ejecutantes. Si el artista, intérprete o ejecutante, cede sus derechos al productor de fonogramas al autorizar la fijación de sus interpretaciones, entonces es valioso para el artista tener el derecho de remuneración equitativa para los casos contemplados en el artículo 12 de la Convención de Roma.

Los productores de fonogramas, por su parte, podrían estar en una posición de desventaja cuando negocian licencias con entidades que tienen mayor poder económico, usualmente organismos de radiodifusión compuestos por grandes televisoras o estaciones de radio. ${ }^{23}$ Es por ello que el artículo 12 de la Convención de Roma también cubre a los pro-

20 Véase Lypszyc, Delia, Copyright and Neighboring..., cit., p. 385.

21 Idem.

22 Ibidem, pp. 385 y 386.

23 Idem; Hilty, Reto M. y Peukert, Alexander, "Equitable Remuneration in Copyright Law: The Amend German Copyright Act as a Trap for Entertainment Industry in the U.S.?", Cardozo Arts and Entertainment Law Fournal, vol. 22, 2004, pp. 401 y 413-414. 
ductores de fonogramas. ${ }^{24}$ Después de todo, el productor de fonogramas tampoco tiene un gran número de derechos, sino que solamente tiene el derecho de autorizar o prohibir la reproducción directa o indirecta de sus fonogramas. ${ }^{25}$

Consecuentemente, tanto el artista, intérprete o ejecutante, como el productor de fonogramas, tienen una válvula de escape a estos derechos un tanto limitados. Como se ha mencionado, dicha válvula se encuentra en el artículo 12 del propio Convenio de Roma: "Cuando un fonograma se utilice... directamente para la radiodifusión o para cualquier otra forma de comunicación al público, el utilizador abonará una remuneración equitativa... a los artistas intérpretes o ejecutantes, o a los productores de fonogramas, o a unos y otros".

La legislación de cada país determinará a quiénes se les otorgará esa remuneración equitativa, si a los artistas intérpretes o ejecutantes, o a los productores de fonogramas, o a ambos. En el caso de la legislación nacional, dicho derecho fue otorgado a unos y otros, en los artículos 117 bis y 131 bis respectivamente. Hasta aquí es importante notar que el artículo 12 de la Convención de Roma no le da a este derecho el carácter de irrenunciable. Si bien, este derecho de remuneración equitativa ya estaba presente en la Ley Federal del Derecho de Autor de 1956, el mismo no se incorporó a la Ley Federal del Derecho de Autor de 1996, por lo que el decreto de reformas del 23 de julio de 2003 lo incorpora nuevamente en el sistema jurídico mexicano. ${ }^{26}$

Para el caso de los derechos de autor, la historia es totalmente diferente. Este tipo de derecho de remuneración equitativa establecido por el artículo 26 bis de la Ley Federal del Derecho de Autor no tiene razón de existir debido a que todos los autores tienen asegurados en las fracciones II y III del artículo 27 del mismo ordenamiento, tanto el derecho exclusivo de comunicación pública como el de transmisión pública o radiodifusión. Derechos que incorporan perfectamente los derechos de transmisión o comunicación al público establecidos por los artículos 11 bis, 11 ter, 14(1) (ii) y 14 bis (1) del Convenio de Berna. Es decir, para los autores, el Conve-

24 Idem.

25 Convenio de Roma, artículo 10.

26 Véase Parra Trujillo, Eduardo de la, "Comentarios a las reformas a la Ley Federal del Derecho de Autor", Revista de Derecho Privado, núm. 8, mayo-agosto de 2004, pp. 95 y 101 . 
nio de Berna da una amplia gama de derechos y no contempla algo equivalente al artículo 12 del Convenio de Roma, porque aquello ya lo está otorgando ampliamente bajo los preceptos ya mencionados del mismo. ${ }^{27}$

Del dictamen que aprueba el decreto que nos ocupa, se desprende el origen del precepto legal: "A efecto de que no se piense que la Ley protegerá más a los artistas e intérpretes que a los propios autores, las comisiones dictaminadoras decidieron establecer la misma precisión en el apartado correspondiente a los derechos de los autores....". ${ }^{28}$

Este razonamiento pasa por alto la circunstancia que llevó a la creación del concepto de remuneración equitativa bajo la Convención de Roma. Además, se ignora que los autores ya tienen el derecho sobre la comunicación pública y la transmisión asegurados en las fracciones II y III del propio artículo 27 de la Ley Federal del Derecho de Autor, derechos derivados del Convenio de Berna. De acuerdo con el dictamen, este derecho es creado a fin "de que no se piense" que la ley protege más a unos que a otros. Sin embargo, el resultado es exactamente lo contrario, debido a que el artículo 26 bis, contiene derechos para los autores que ya se encuentran establecidos por las fracciones II y III del artículo 27 de la Ley Federal del Derecho de Autor. Es decir, termina protegiendo más a los autores que a los artistas, intérpretes y ejecutantes.

\section{LAS SENTENCIAS DE LA SUPREMA \\ CorTe de JUSTICIA DE LA NACiÓN}

\section{Cinemex Toluca II}

En la resolución del 10 de junio de 2005, la Segunda Sala de la Suprema Corte de Justicia de la Nación, resuelve el Amparo en Revisión 105/2005. ${ }^{29}$ Este recurso fue interpuesto por la parte quejosa en contra

27 Véase Von Lewinski, Silke, International Copyright Law and Policy, Nueva York, Oxford University Press, 2008, p. 148.

28 Senado de la República, "Dictamen que aprueba el decreto por el que se reforman y adicionan diversos artículos de la Ley Federal del Derecho de Autor", disponible en http:// legislacion.scjn.gob.mx/LF/DetalleProcesoLeg.aspx?'IdLey=9233 EIdRef=3 EIdProc =2 (visitada el 12 de enero de 2015).

29 Segunda Sala de la Suprema Corte de Justicia de la Nación, Amparo en Revisión 105/2005, Cinemex Toluca II, S. A. de C. V. et al., 10 de junio de 2005. Sentencia obte- 
de la resolución en la que el juez séptimo de distrito en materia administrativa en el Distrito Federal, sobreseyó el juicio de amparo indirecto promovido por ésta. ${ }^{30}$ En este amparo se reclamó la inconstitucionalidad de los artículos 26 bis, 83 bis, 117 bis, así como el 118 de la Ley Federal del Derecho de Autor, reformados y adicionados mediante el decreto de reformas de fecha 23 de julio de 2003. La Segunda Sala sostuvo la constitucionalidad de dichos preceptos legales, por lo que no concedió el amparo a la quejosa. ${ }^{31}$

La parte quejosa estaba conformada por varias sociedades anónimas, entre ellas, Cinemex Toluca II, S. A. de C. V., "dedicadas entre otras actividades comerciales, a la comunicación pública de obras cinematográficas en salas de cine mediante su exhibición o proyección....". ${ }^{32}$ Nos referiremos a estas sociedades como la parte quejosa, o bien los quejosos.

La parte quejosa argumentaba que las reformas eran contrarias a la Constitución Política de los Estados Unidos Mexicanos por varias razones. Primeramente, argumentaban la falta de certeza de los preceptos legales en cuanto a la persona que debería recibir la remuneración establecida por los mismos. Además, debido a que los quejosos se dedicaban a la exhibición de obras cinematográficas en sus salas de cine, argumentaban que el artículo 26 bis, propiciaba dobles o triples pagos por concepto de regalías por la exhibición de una misma película. Así, los quejosos tendrían que pagar no solamente al productor de la película, que es de quien tradicionalmente adquieren el derecho de exhibirla, sino que también al director de la misma, a los autores de los guiones, a los autores de las composiciones musicales, fotógrafos, caricaturistas; es decir, a todos aquellos que la propia ley considera autores de la obra cinematográfica. ${ }^{33}$ Se alegó

nida a través del módulo de acceso a la información de la Suprema Corte de Justicia de la Nación, disponible en http://www2.scjn.gob.mx/ConsultaTematica/PaginasPub/TematicaPub. aspx (visitada el 13 de enero de 2015). Del mismo procedimiento se desprenden diversas tesis aisladas, entre las mismas se encuentra la siguiente: "REGALÍAS PREVISTAS POR El artículo 26 bis De la ley Federal del Derecho De AUtor. Notas Que las Distinguen De los Derechos PATRIMONIALES....", tesis 2a. CXXIII/2005, Semanario Fudicial de la Federación y su Gaceta, Novena Época, t. XXII, diciembre de 2005, p. 404.

30 Segunda Sala de la Suprema Corte de Justicia de la Nación..., cit., pp. 38 y 39.

31 Ibidem, p. 180.

32 Ibidem, p. 4.

33 Ibidem, pp. 6 y 7; Ley Federal del Derecho de Autor, artículo 97. 
que esta falta de certeza violaba las garantías de seguridad jurídica y legalidad, contenidas en los artículos 14 y 16 constitucionales. ${ }^{34}$

La falta de certeza alegada, se debía principalmente a los derechos irrenunciables que establece el artículo 26 bis de la Ley Federal del Derecho de Autor. Ello porque normalmente todas las personas antes mencionadas al colaborar en la realización de una obra cinematográfica, ceden sus derechos al productor, y éste es quien comercializa y distribuye la película, cobrando así las regalías. Sin embargo, cuando la legislación otorga derechos irrenunciables a todas estas personas, las mismas pueden en cualquier momento exigir ese derecho de regalías a quien comunique, transmita o ponga a disposición la obra, aunque lo hayan cedido en un contrato y aunque el productor ya les haya pagado por su participación. Ello porque los derechos irrenunciables establecidos por el artículo 26 bis harían nula cualquier cláusula contractual en la que dichos derechos fuesen cedidos al productor. Entonces, no se tendría la certeza de hacer solamente un pago al productor, o hacer algún otro pago con posterioridad. Estimamos que este problema también se presenta con los artículos 117 bis y 131 bis de la Ley Federal del Derecho de Autor, que establecen el mismo derecho de remuneración equitativa irrenunciable en favor de artistas, intérpretes y ejecutantes, así como de productores de fonogramas respectivamente.

En el mismo concepto de violación, la parte quejosa argumentó que la redacción del artículo 26 bis de la Ley Federal del Derecho de Autor propiciaba pagos dobles, debido a que establece que la regalía será en favor del "autor y su causahabiente". ${ }^{35}$ En este sentido, la Segunda Sala interpretó este artículo refiriéndose solamente al autor, o a aquel o aquellos herederos que han adquirido ese derecho mediante sucesión, debido a que el derecho de remuneración en cuestión es irrenunciable. ${ }^{36}$

La Segunda Sala de la Suprema Corte, sostuvo que las provisiones estableciendo estos pagos de regalías no generan falta de certeza ya que la determinación del monto de las mismas está claramente establecido por dichos preceptos legales. ${ }^{37}$ Asimismo, la Segunda Sala sostuvo que

\footnotetext{
34 Ibidem, p. 4.

35 Ibidem, p. 34.

36 Ibidem, pp. 124 y 125.

37 Ibidem, p. 134.
} 
aunque el usuario de una obra tuviera que compensar al productor y al titular de una de estas regalías, esto no constituye un doble pago por el mismo concepto, ya que ambos pagos se derivan de cosas distintas. ${ }^{38} \mathrm{De}$ acuerdo con este razonamiento, los artículos 26 bis, 117 bis y 118 de la Ley Federal del Derecho de Autor son certeros, por lo que los usuarios tienen que pagar tanto al productor de la obra cinematográfica como a aquellos titulares de las regalías establecidas por dichos preceptos legales.

La Segunda Sala sostuvo que los derechos patrimoniales incluyen, entre otros, el derecho sobre la explotación por reproducción, distribución, comunicación al público, así como la transmisión. ${ }^{39}$ Asimismo, sostuvo que los derechos patrimoniales pueden transferirse mediante contrato. Sin embargo, la Suprema Corte sostuvo también que los derechos sobre las regalías establecidos por los artículos 26 bis, 117 bis y 131 bis de la legislación que nos ocupa, no son derechos patrimoniales, sino un tipo de derechos distintos que no pueden ser transferidos mediante contrato. ${ }^{40} \mathrm{El}$ resultado de interpretar el derecho de regalías como un tipo de derecho distinto de los patrimoniales tiene importantes consecuencias. Al igual que varios países de la tradición romano germánica, la Ley Federal del Derecho de Autor mexicana sigue la concepción dualista de los seguidores de Hegel, dividiendo así los derechos de los autores en patrimoniales y morales. ${ }^{41}$ Sin embargo, este razonamiento parece crear de un plumazo un nuevo tipo de derecho, distinto de los derechos patrimoniales y los derechos morales. ${ }^{42}$

En otro concepto de violación, la parte quejosa argumentaba que, al no provenir de un contrato, este derecho de regalías más bien constituía un impuesto contrario a los principios básicos que para el cobro de impuestos establece el artículo 31 fracción IV de la Constitución Política de los Estados Unidos Mexicanos. ${ }^{43}$ Ello debido a que las características de los derechos de regalías establecidos por el decreto que nos ocupa, es contrario a dichos principios, como el de proporcionalidad, el de equidad y el que establece que la contribución tenga por destino el gasto público. Además, la parte quejosa argumentó que de acuerdo con la fracción IV del ar-

38 Ibidem, p. 145.

39 Ibidem, p. 134.

40 Ibidem, p. 131.

41 Véase Netanel, Neil, "Alienability Restrictions...", cit., p. 21.

42 Véase Segunda Sala de la Suprema Corte de Justicia de la Nación..., cit., p. 131.

43 Ibidem, pp. 36 y 37. 
tículo 74 constitucional, cualquier reforma o ley que establezca impuestos debe ser discutida primero en la Cámara de Diputados del Congreso. En este caso, la iniciativa fue discutida primero en el Senado, violando así los procedimientos constitucionales para crear leyes de carácter impositivo. Este concepto de violación fue declarado infundado por la Segunda Sala, debido a que el este pago de regalías, no es "expresión de la potestad tributaria del Estado", por lo que no se encuentra regido por los principios constitucionales citados con anterioridad. ${ }^{44}$

La Segunda Sala explicó extensivamente las características de los impuestos y cómo éstos son diferentes de las regalías establecidas por el decreto cuya constitucionalidad analizaba. Refirió, entre otras características, que los impuestos son para sufragar el gasto público, y que las autoridades hacendarias tienen a su disposición procedimientos administrativos especiales para cobrarlos. ${ }^{45}$ Contrariamente, los derechos de regalías establecidos por el decreto están destinados a particulares, entre ellos autores, artistas, intérpretes y ejecutantes. Como soporte de sus afirmaciones, la Segunda Sala de Justicia citó a varios académicos del área de derecho fiscal. Asimismo, afirmó que el hecho de que la obligación a pagar regalías provenga de la Ley y no de un contrato, no transforma las regalías en impuestos.

En su análisis de los conceptos de violación, la Segunda Sala basó fuertemente su decisión en la exposición de motivos contenida en la historia legislativa, dando gran deferencia a las políticas públicas que el Congreso plasmó en dicha historia legislativa.

Es de estimarse que el argumento más importante para lograr la inconstitucionalidad del decreto por la parte quejosa hubiese sido alegar que las provisiones del mismo que establecen el sistema de regalías irrenunciables, son contrarias al artículo 1705(3) del TLCAN ${ }^{46}$ Ello debido a que, de acuerdo con la interpretación que la propia Suprema Corte ha dado al artículo 133 constitucional, los tratados internacionales, prevalecen sobre cualquier ley federal o estatal. ${ }^{47}$ De haberse encontrado la

44 Ibidem, p. 118.

45 Ibidem, p. 116.

46 Ibidem, p. 29.

47 “Tratados InTERnAGIONALES. SE UBICAN JERÁRQUICAMENTE POR ENCIMA DE LAS LEYES FEDERALES....", tesis P. LXXVII/99, Semanario Fudicial de la Federación y su Gaceta, Novena Época, t. X, noviembre de 1999, p. 46. 
contradicción entre las provisiones del decreto y el artículo 1705(3) del TLCAN, en esos tiempos, el resultado hubiese sido la inconstitucionalidad de las provisiones del decreto. Es importante mencionar que en la actualidad, con el nuevo criterio que la Suprema Corte de Justicia de la Nación ha establecido mediante contradicción de tesis, ello no conllevaría a un problema de constitucionalidad del decreto sino más bien sería una cuestión de mera legalidad; es decir, las consecuencias serían diferentes. ${ }^{48}$ De acuerdo con nuevo este criterio, la contradicción entre una ley secundaria y un tratado internacional, generaría la inconstitucionalidad de la ley únicamente cuando el tratado internacional sea en materia de derechos humanos. Al no ser el TLCAN un tratado internacional sobre derechos humanos, el día de hoy la contradicción de alguna ley secundaria con alguno de sus preceptos, no generaría la inconstitucionalidad de la misma sino que solamente daría lugar a lo que se conoce como amparo de legalidad. Es decir, no procedería el Amparo Indirecto para analizar la inconstitucionalidad derivada de ello, tampoco la revisión en amparo directo. Si bien el tratado internacional que no versa sobre derechos humanos, sigue prevaleciendo sobre una ley secundaria, su contradicción será una cuestión de legalidad y no de constitucionalidad de la ley secundaria.

Sin embargo, dado que en aquellos años la contrariedad de los artículos 26 bis, 117 bis y 118 de la Ley Federal del Derecho de Autor con el artículo 1705(3) del TLCAN, hubiese podido llevar a la inconstitucionalidad de los mismos, es de gran interés ver el escaso análisis con el que este concepto de violación fue abordado por la Segunda Sala de la Suprema Corte. De las 182 páginas de la sentencia, menos de 10 abordan dicho argumento y en buena medida es para citar textualmente provisiones de varios tratados internacionales. ${ }^{49}$

48 “Cuestión constitucional. Para efectos de la Procedencia del RecurSO DE REVISIÓN EN AMPARO DIRECTO, SE SURTE CUANDO SU MATERIA VERSA SOBRE LA COLISIÓN ENTRE UNA LEY SECUNDARIA Y UN TRATADO INTERNACIONAL, O LA INTERPRETACIÓN DE UNA NORMA DE FUENTE CONVENCIONAL, Y SE ADVIERTA PRIMA FACIE QUE EXISTE Un DERECHO HUMANO EN JUEGO....", tesis P./J. 22/2014 (10a.), Gaceta del Semanario Fudicial de la Federación, libro 5, abril de 2014, t. I, p. 94.

49 Véase Segunda Sala de la Suprema Corte de Justicia de la Nación..., cit., pp. 169179. 
La parte quejosa planteó la cuestión de manera diferente a lo expuesto en la primera parte de este ensayo. En lugar de enfocarse en la contradicción de los artículos 26 bis, 117 bis, y 131 bis de la Ley Federal del Derecho de Autor con el artículo 1705(3) del TLCAN, su argumento se basó en que los artículos 26 bis y el 83 bis del mismo decreto, son contrarios no solamente al propio artículo 1705(3) del TLCAN, sino que además contradicen el artículo 6 bis del Convenio de Berna, así como al artículo XI de la Convención Interamericana sobre Derechos de Autor en Obras Literarias, Científicas y Artísticas. ${ }^{50}$ Por cierto, esta última es inaplicable desde hace alrededor de medio siglo, sin que la quejosa o algún tribunal de los que conoció el caso repararan en el asunto. De esta manera, se diluyó el argumento que más posibilidades tenía. Además, la quejosa solamente centró su argumentación en el artículo 26 bis, y dejó fuera los artículos 117 bis y 131 bis de la Ley Federal del Derecho de Autor. Preceptos que tienen más relación que el artículo 83 bis del mismo ordenamiento, ya que al igual que el artículo 26 bis, los artículos 117 bis y 131 bis establecen la remuneración irrenunciable a cargo de quien comunique al público o transmita alguna de las obras en cuestión. Toda esta situación ha seguido generando litigios, como el Amparo Directo 11/2010, resuelto posteriormente por la Primera Sala de la Suprema Corte.

Así las cosas, la Segunda Sala de la Suprema Corte de Justicia de la Nación interpretó el concepto de violación de la siguiente manera: "la pretensión de las quejosas se centra... en demostrar... que los referidos tratados reconocen ese derecho a uno o a otro, en tanto que el precepto impugnado lo otorga a ambos". ${ }^{51}$

Tanto el argumento presentado por la quejosa como la lectura del mismo por parte de la Segunda Sala, distan mucho de la verdadera contrariedad entre el artículo 1705(3) del TLCAN y los preceptos contenidos en la Ley Federal del Derecho de Autor. Contrariedad centrada en la libre disposición de los derechos establecida por el artículo 1705(3) del TLCAN, bajo la cual no está permitido que los derechos sean irrenunciables, intransferibles o inalienables.

Después de citar textualmente los preceptos de los tratados internacionales ya mencionados, e incluso el artículo 14 ter del Convenio de Ber-

50 Ibidem, p. 26.

51 Ibidem, p. 171. 
na, el cual no guarda relación alguna con el tema por incluir lo que se conoce como droit de suite, la Segunda Sala concluyó que bajo esas provisiones, especialmente el artículo 6o. bis del Convenio de Berna, el autor tiene derecho a transferir sus derechos, y que el derecho a recibir "una participación en las ventas de la obra posteriores a la primera cesión operada por el autor", es irrenunciable. ${ }^{52}$

Una interpretación adecuada de los artículos 6o. bis y 14 ter del Convenio de Berna, invariablemente concluiría que los mismos establecen diferentes derechos. El primero establece los derechos morales, que son independientes a los derechos patrimoniales, en tanto que el segundo establece un derecho de remuneración por la venta subsecuente de pinturas, manuscritos originales $\mathrm{u}$ otras piezas de arte originales.

En cuanto a los derechos morales, el artículo 6o. bis del Convenio de Berna establece que los mismos son independientes a los derechos patrimoniales. Lo anterior significa que aunque los derechos patrimoniales se transfieran, los derechos morales se conservan independientemente de aquéllos. ${ }^{53}$ Existe incluso la discusión de si los derechos morales pueden ser transferidos bajo el artículo 6o. bis del Convenio de Berna, ${ }^{54}$ cosa que en el sistema jurídico mexicano es imposible por así prohibirlo los artículos 18 y 19 de la Ley Federal del Derecho de Autor, estableciendo este último que: "el derecho moral se considera unido al autor y es inalienable, imprescriptible, irrenunciable e inembargable". ${ }^{55}$ De acuerdo al artículo 6o. bis del Convenio de Berna, los derechos morales cubren el derecho de paternidad de la obra, así como el derecho de integridad de la misma, oponiéndose a cualquier distorsión, mutilación o modificación que cause perjuicio al honor o reputación del autor. Asimismo, establece que los derechos morales deben durar al menos lo mismo que los patrimoniales. Sin embargo, la legislación mexicana va más allá del artículo 6o. bis del Convenio de Berna, ya que establece que sus artículos 18 y 19 son "perpetuos" e "imprescriptibles". Por otra parte, el alcance de los mismos bajo

52 Ibidem, p. 178.

53 Véase Ricketson, Sam y Ginsburg, Jane C., International Copyright and Neighboring Rights. The Berne Convention and Beyond, 2a. ed., Nueva York, Oxford University Press, 2006, p. 599 .

54 Ibidem, p. 600.

55 Ley Federal del Derecho de Autor, artículo 19. 
el artículo 21 de la Ley Federal del Derecho de Autor es mayor a los derechos de paternidad e integridad establecidos por el Convenio de Berna.

En resumidas cuentas, nunca se ha concluido ni interpretado que el artículo 6o. bis del Convenio de Berna otorga al autor el derecho de transferir sus derechos patrimoniales. ${ }^{56}$ Simplemente establece que, en caso de ser así, los derechos morales son independientes de aquéllos.

Ahora bien, el artículo 14 ter del Convenio de Berna establece el denominado "droit de suite". Este derecho, se puede desprender de su nombre, nace en Francia como respuesta a que los artistas visuales o pintores no tenían las mismas oportunidades que los escritores o compositores. ${ }^{57}$ Entonces por cuestión humanitaria y porque se determinaba que en su tiempo de vida, el artista tal vez no podría recibir la compensación adecuada por sus pinturas, nace este derecho. ${ }^{58}$ Es un derecho a obtener una participación por cada venta subsecuente de la obra, pero del soporte físico original de la misma. Es decir, si el cuadro original elaborado por determinado pintor se vende en una subasta, entonces, él o sus herederos recibirán una participación por esa venta. Sin embargo, el artículo 14 ter, no se limita a artistas visuales sino que abarca todo tipo de obras de arte originales, y otorga además a escritores y compositores esta participación por las ventas subsecuentes de sus manuscritos originales. De acuerdo con el segundo párrafo de dicho precepto legal, la protección no es obligatoria para los países miembros, sino opcional. Este precepto ha sido incorporado en parte por el propio decreto que nos ocupa, adicionando el artículo 92 bis a la Ley Federal del Derecho de Autor.

Como se puede ver, el artículo 14 ter del Convenio de Berna no tiene relación alguna con la interpretación dada al mismo por la resolución que nos ocupa. Es decir, es un derecho a obtener una participación de la venta del cuadro original o de manuscritos originales. Entendiéndose lo anterior como un derecho sobre soportes materiales originales y no una participación irrenunciable "en las ventas de la obra posteriores a la primera cesión operada por el autor" ${ }^{59} \mathrm{El}$ significado del término ventas de

56 Véase Ricketson, Sam y Ginsburg, Jane C., International Copyright ..., cit., pp. 599-614; Ilardi, Alfredo y Blakeney, Michael, International Encyclopedia of..., cit., p. 1066; Goldstein, Paul, International Intellectual Property Law, 2a. ed., Nueva York, Foundation Press, p. 346.

57 Cfr. Ricketson, Sam y Ginsburg, Jane C., International Copyright..., cit., pp. 669 y 670.

58 Ibidem, p. 671.

59 Segunda Sala de la Suprema Corte de Justicia de la Nación..., cit., p. 178. 
la sentencia, encierra un significado mucho más amplio que la venta del soporte material; más bien refiere a cualquier cesión remunerada de alguno de los derechos.

De todo lo anterior, se concluye que la Segunda Sala dedujo erróneamente que el Convenio de Berna establece en su artículo 6o. bis el derecho a transmitir la obra, y que el artículo 14 ter del mismo afirma el derecho inalienable a una participación, por la utilización de la obra en la comunicación al público o en su transmisión.

Por otro lado, resulta cuestionable la aplicabilidad del artículo 11 de la Convención Interamericana sobre Derecho de Autor en Obras Literarias, Científicas o Artísticas. ${ }^{60}$ Ello debido a que la misma ha sido desplazada por el artículo 18 de la Convención Universal sobre Derecho de Autor, de la que México forma parte. Esta última es un puente entre aquélla y el Convenio de Berna, ya que el artículo 17 de la Convención Universal sobre Derecho de Autor establece que no será aplicable cuando el Convenio de Berna sea aplicable, o cuando las obras provienen de países que se retiren del Convenio de Berna después del 1o. de enero de $1951 .{ }^{61}$ Es decir, la Convención Universal sobre Derecho de Autor prevalece sobre la Convención Interamericana sobre Derecho de Autor en Obras Literarias, Científicas o Artísticas, y a su vez cede la aplicación de ambas en favor del Convenio de Berna. Actualmente, la Convención Interamericana sobre Derecho de Autor en Obras Literarias, Científicas o Artísticas ha sido caracterizada solamente por su valor histórico, ya que "ha sido sustituida por su accesión al Convenio de Berna o a la Convención Universal sobre Derecho de Autor". ${ }^{62}$

La Segunda Sala de la Suprema Corte de Justicia de la Nación no reparó en que la Convención Interamericana sobre Derecho de Autor en Obras Literarias, Científicas o Artísticas ya no es vigente. Tampoco abordó el alcance del artículo 1705(3) del TLCAN. De haber sido así, habría tenido que concluir que dicho precepto legal prohíbe cualquier limitación a la libre disposición de los derechos, por lo que cualquier cuestión irrenunciable en alguna disposición legal sería contraria al mismo. En este

$60 \quad$ Ibidem, p. 173.

61 Véase Convención Universal sobre Derecho de Autor, artículos 17 y 18; Ricketson, Sam y Ginsburg, Jane C., International Copyright..., cit., p. 1182; véase Ilardi, Alfredo y Blakeney, Michael, International Encyclopedia of ..., cit., p. 1098.

62 Lypszyc, Delia, Copyright and Neighboring..., cit., p. 614. 
sentido, una correcta interpretación del artículo 1705(3) del TLCAN habría determinado que son contrarios al mismo, por lo menos, los artículos 26 bis, 117 bis, 117 y 131 bis de la Ley Federal del Derecho de Autor.

\section{La contradicción de tesis}

Mediante el procedimiento de Contradicción de tesis 25/2005-PL, el Pleno de la Suprema Corte de Justicia de la Nación, desechó el criterio de la resolución anterior, al menos en lo que respecta al derecho de regalías establecido por el artículo 26 bis del ordenamiento en estudio en favor de los autores por la comunicación al público o transmisión de sus obras. ${ }^{63} \mathrm{La}$ decisión no cubre explícitamente los derechos de los artistas, intérpretes, ejecutantes, tampoco los de los productores de fonogramas. Por lo tanto, los derechos para ellos continúan de la misma manera. Es decir, tanto los artistas, intérpretes y ejecutantes, como los productores de fonogramas, no pueden renunciar mediante contrato a la remuneración establecida por los artículos 117 bis y 131 bis de la Ley Federal del Derecho de Autor. ${ }^{64}$ La tesis siguiente resume el razonamiento de la Suprema Corte en este sentido: "DERECHO A PERCIBIR REGALÍAS... ES TRANSMISIBLE A TERCEROS EN VIDA DEL AUTOR... De ese modo, el autor, una vez que el derecho referido ha entrado a formar parte de su patrimonio, está facultado para transmitirlo....". ${ }^{65}$

Claramente se aprecia que la Suprema Corte interpretó el artículo 26 bis en sentido contrario al significado literal de sus palabras. Citando literalmente la exposición de motivos de varios dictámenes rendidos durante el proceso legislativo, mismos que no soportan su conclusión, la Suprema Corte recalcó una clara "política de protección del derecho de autor, a

63 La ejecutoria tiene los siguientes datos de localización: Pleno de la Suprema Corte de Justicia de la Nación, contradicción de tesis 25/2005-PL. Entre las sustentadas por la primera y la segunda salas de la Suprema Corte de Justicia de la Nación, Semanario fudicial de la Federación y su Gaceta, Novena Época, t. XXVII, enero de 2008, p. 652.

64 Sin embargo, dada su similitud, en el futuro los litigantes podrían argumentar que este criterio también es aplicable a los derechos contenidos en los artículos 117 bis y 131 bis del ordenamiento en comento.

65 Pleno de la Suprema Corte de Justicia de la Nación, contradicción de tesis 25/2005PL. Entre las sustentadas por la primera y la segunda salas de la Suprema Corte de Justicia de la Nación, tesis P./J. 103/2007, Semanario Fudicial de la Federación y su Gaceta, Novena Época, t. XXVI, diciembre de 2007, p. 7. 
través de la reincorporación del derecho de regalías en estudio". ${ }^{66}$ De allí, concluyó que "este tribunal no debe sustituirse en la voluntad del legislador, no de los autores que, en cada caso concreto, deben tener el poder decisorio para determinar... la transmisión del derecho de regalías". ${ }^{67}$ Es decir, debido a que notó una política pública de protección a los autores en la exposición de motivos, y que consideró importante un poder decisorio en la autonomía de la voluntad de los mismos, interpretó exactamente al contrario la literalidad del artículo 26 bis en análisis. Estimamos que basarse en la exposición de motivos para interpretar en sentido contrario las palabras un precepto legal genera incertidumbre, ya que la voluntad del legislador debe reflejarse en el propio precepto legal. Aceptar lo contrario, obligaría al gobernado no solamente a cumplir con los preceptos legales, sino también con las exposiciones de motivos. Las mismas enuncian tantas cosas, que uno podría basarse en ellas para concluir de igual manera, dos posturas opuestas. Ello porque su objeto y su técnica es distinta a la de los preceptos jurídicos. Aun así, la citada exposición de motivos no lleva a la conclusión sostenida por el alto tribunal. Ello genera incertidumbre, ya que en algunas ocasiones se llega al absurdo, como ahora, de utilizar una vaga exposición de motivos para interpretar en sentido contrario la literalidad de un precepto legal.

De acuerdo con el voto disidente, si el precepto legal contiene un derecho irrenunciable, es precisamente porque se pretende que el mismo no sea transmisible entre vivos. Es decir, solamente se puede transmitir mediante sucesión, por ello el término "causahabiente". Asimismo, estableció que esto se debe a que el legislador buscaba lograr un equilibrio entre las partes y "evitar presiones al autor destinadas a provocar su renuncia de ese derecho". ${ }^{68}$ Ello por la falta de equilibrio entre el autor y algún productor con mayor poder económico durante una negociación. De acuerdo con la sentencia suscrita por la mayoría, el carácter de irrenunciable contenido en el artículo 26 bis consiste en que el autor no puede

66 Pleno de la Suprema Corte de Justicia de la Nación, contradicción de tesis 25/2005PL. Entre las sustentadas por la primera y la segunda salas de la Suprema Corte de Justicia de la Nación, Semanario Fudicial de la Federación y su Gaceta, Novena Época, t. XXVII, enero de 2008, p. 682.

67 Ibidem, p. 686.

68 Idem. 
transmitir su derecho antes de que haya entrado en su patrimonio. ${ }^{69}$ Sin embargo, los ministros que suscribieron el voto disidente sostuvieron que dicha interpretación es incorrecta, debido a que el autor ya se encuentra imposibilitado a "disponer de tal derecho antes de que haya entrado en su patrimonio". ${ }^{70}$ Asimismo, sostuvieron que "la sentencia confunde el derecho y la actualización del supuesto normativo...". ${ }^{71}$ Ello porque el derecho de regalías ya se encuentra en la esfera del autor debido a que así lo dispuso el legislador y que su naturaleza es irrenunciable porque también lo estableció el legislador. Es decir, el autor por serlo ya tiene ese derecho. Sería imposible que un autor renunciara a que nazca dicho derecho, de ser así, no sería autor, ya que el legislador le ha otorgado ese derecho al autor.

El voto disidente también sostuvo que en el sistema jurídico mexicano existen otros derechos irrenunciables, como el derecho de alimentos, o el derecho al salario, entre otros. De acuerdo con el mismo, son derechos irrenunciables porque el legislador quiere conservarlos en la esfera de su titular, dentro del mismo argumento, se pregunta "qué intereses subyacen en el derecho de regalías, ¿no son acaso los mismos?". ${ }^{72}$ Para los ministros que suscriben el voto disidente lo irrenunciable del derecho, "lleva implícito lo intransferible... lo contrario... quitaría todo sentido a su consagración en la norma". ${ }^{73}$

A diferencia de la Segunda Sala en el Amparo en Revisión 105/2005 analizado anteriormente, la contradicción de tesis que nos ocupa sostuvo que el derecho de remuneración contenido en el artículo 26 bis de la Ley Federal del Derecho de Autor es un derecho patrimonial. Es decir, no se trata de un nuevo tipo de derecho, distinto de los derechos patrimoniales o de los derechos morales. La Suprema Corte sostuvo que el legislador ha establecido dos tipos de derechos, los morales y los patrimoniales. Asimismo, reconoció que aunque la doctrina pudiese ofrecer otras perspectivas, la Corte seguiría la adoptada por el legislador a fin de resolver la cuestión lo más claro posible. ${ }^{74}$ Este enfoque sigue la doctrina dualista expli-

69 Ibidem, p. 694.

70 Idem.

71 Idem.

72 Ibidem, p. 696.

73 Ibidem, p. 697.

74 Ibidem, pp. 665 у 666. 
cada anteriormente, abandonando así el criterio de tres tipos de derechos adoptado por la Segunda Sala.

Tanto la Contradicción de tesis decidida por el Pleno, como la sentencia de amparo resuelta por la Segunda Sala, dan gran deferencia a la historia legislativa. Ambas opiniones citan extensivamente la exposición de motivos vertida en los dictámenes derivados del proceso legislativo, incluyendo el ejemplo incluido en uno de ellos sobre los herederos de Pedro Infante, quienes en 1999 recibieron $\$ 4,288.56$ por concepto de regalías por la transmisión de sus películas en señal abierta y por televisión restringida. ${ }^{75}$ Lo interesante aquí, es que utilizando las mismas partes de la exposición de motivos, ambas sentencias lleguen a conclusiones totalmente opuestas.

Finalmente, la sentencia de contradicción de tesis concluye que "corresponde al legislador y no a este alto tribunal, decidir si agrega al artículo 26 bis de la Ley... la característica de intransmisibilidad...el derecho de regalías... es un derecho irrenunciable, aunque sí es transmisible en vida del autor" ${ }^{76}$

\section{Conclusiones}

Sostener que irrenunciable no es lo mismo que intransferible conlleva a una interpretación opuesta al sentido literal de las palabras del precepto legal. Se pudo haber llegado al mismo resultado invocando el artículo 1705(3) del TLCAN, que prohíbe a las partes limitar la libre transferencia de derechos. Por jerarquía normativa este precepto debió prevalecer sobre la ley secundaria. Las consecuencias de dicha interpretación aún siguen teniendo efectos en el sistema jurídico mexicano, como el Amparo Directo 11/2010 resuelto por la Primera Sala de la Suprema Corte de Justicia de la Nación.

75 Ibidem, p. 677; Segunda Sala de la Suprema Corte de Justicia de la Nación..., cit., p. 79.

76 Ibidem, p. 688. 